\title{
Athènes 1833 : la guerre pour la capitale de l'État- Nation
}

Athens 1833: Warfare for the Capital of the Nation-State

Yannis Tsiomis

\section{(2) OpenEdition}

Journals

Édition électronique

URL : http://journals.openedition.org/etudesbalkaniques/104

ISSN : 2102-5525

\section{Éditeur}

Association Pierre Belon

\section{Édition imprimée}

Date de publication : 1 janvier 2005

Pagination : $173-176$

ISBN : 2-910860-05-1

ISSN : $1260-2116$

\section{Référence électronique}

Yannis Tsiomis, «Athènes 1833 : la guerre pour la capitale de l'État-Nation », Études balkaniques [En ligne], 12 | 2005, mis en ligne le 01 mai 2006, consulté le 05 mai 2019. URL : http:// journals.openedition.org/etudesbalkaniques/104

Ce document a été généré automatiquement le 5 mai 2019.

Tous droits réservés 


\title{
Athènes 1833 : la guerre pour la capitale de l'État-Nation
}

\author{
Athens 1833: Warfare for the Capital of the Nation-State
}

\section{Yannis Tsiomis}

1 Après la lutte pour l'indépendance (1821-1829) et la création de l'État grec (1830), la question de la capitale se transforme dès 1832 en guerre pour la capitale. Athènes est alors un village sec et ruiné (ils ne restent que soixante maisons en état de délabrement), qui souffre de la comparaison avec d'autres villes et bourgades prospères de la Grèce indépendante.

2 Ces différentes villes prétendantes ont, chacune, des atouts que leurs groupes de pression, s'attachent à promouvoir. Argos, Tripolis, Corinthe, Nauplie (la première capitale), Mégare, Le Pirée, l'Isthme sont à tour de rôle candidates pour devenir « capitale du Royaume ». Et puis il y a Syros bien qu'insulaire, ou Patras, deux centres économiques forts. Il est vrai que nombre de ces villes « ne participent pas à la vie publique » puisque leurs hommes d'affaire, "partagent leur temps entre les marchés européens et leurs comptoirs insulaires regardant avec un peu de mépris cette monarchie d'opérette dont la seule capacité consiste aux références à l'antiquité ». Mais si, dans toutes ces villes, le pouvoir local est fort, si les chefs provinciaux sont bien installés et s'ils font pression avec des appuis locaux et selon un mode clientéliste pour que leur quartier général devienne capitale, simultanément ils ont «besoin d'un espace neutre pour résoudre leurs contradictions et leurs antagonismes régionaux $»^{1}$.

Le 20 mai 1833 - un an et demi avant l'installation du roi et du gouvernement à Athènes, le $1^{\text {er }}$ décembre 1834 - parait dans le journal Athéna un article sur la question de la capitale $^{2}$. Cet article est une des expressions les plus percutantes de toutes les oppositions : «Le moment approche où le peuple de la Grèce apprendra officiellement si l'Isthme ou Athènes seront le siège du Royaume de Grèce: déjà le premier [l'Isthme] détient la majorité de la Nation. Les autres [villes] n'ont recueilli jusqu'ici que les voix de leurs propres habitants et ceux des environs immédiats (...). On nous dit qu'Athènes était 
autrefois le siège des Arts, de la philosophie et de la civilisation; parmi ses ruines existent encore des monuments sacrés parmi lesquels il serait glorieux et profitable que la nouvelle capitale du Royaume soit érigée; gardant son ancien nom et contenant d'admirables antiquités elle devrait rapidement être réhabilitée, par l'affluence de philhellènes ». Mais l'article d' Athéna poursuit en arguant que tous n'adhèrent pas à l'identification de la Grèce moderne à l'antiquité: «Bien sûr nous respectons la gloire d'Athènes classique et admirons les merveilles ancestrales qui subsistent (...) Mais est-il juste de nous laisser prendre entièrement, dans l'enthousiasme, par nos souvenirs historiques et passés, aux dépens des intérêts fondamentaux de tout un territoire national? Parce qu'autrefois Athènes a brillé et aujourd'hui fascine notre imagination, est-il judicieux de sacrifier les vœux et les espérances d'une Nation, à l'ombre des arbres éternels et à l'esthétique de quelques philhellènes, qui brûlant de l'amour du tourisme, vont traverser comme avant [l'indépendance] la Grèce pour offrir leur adoration à l'antiquité respectée? ».

4 Cet article condense bien la situation : Arguments économiques, pouvoirs locaux, héritage du temps de l'occupation ottomane, géopolitique s'entremêlent et dessinent l'aporie dans laquelle se trouve la Grèce, État indépendant à la sortie de l'occupation ottomane. Mais le journal poursuit et sans le savoir donne la clé de la réponse. «L'archéologie est très distante, malgré tout, de la politique et la différence entre extases esthétiques et avantages réels est grande; pourtant les nouveaux orateurs des Athéniens (...) nous promettent que [grâce à elle] la politique des Grandes Cours sera plus favorable, et que, en cas de guerre, nos ennemis Barbares [les Ottomans], reculeront devant la vue de l'Acropole sacrée ». Malgré son ironie le journaliste touche pourtant le fond du problème. Car, justement, l'archéologie sert aussi à faire de la politique et, si Athènes est choisie comme capitale, c'est grâce à son nom, grâce à ses vestiges peu visibles à l'époque. Georg Ludwig Maurer, membre de la régence bavaroise se servira deux ans plus tard dans son livre Das Griechische Volk ${ }^{3}$ de l'argument archéologique pour justifier ce choix. "Quelle ville ou quel site devraient être préférés ? C'était le grand problème. Les Moraïtes [c'est à dire les habitants du Péloponnèse] parlaient d'Argos ou Tripolitza ou Corinthe. Les Stéréohelladites [c'est à dire ceux de la Grèce du centre] parlaient d'Athènes. Colettis défendait bien sûr Mégare ${ }^{4}$. Et l'architecte Gutensohn ${ }^{5}$ parlait du Pirée! Autour du thème de la capitale, qui touchait des intérêts économiques vitaux, les discussions faisaient rage, tant parmi les privés que les officiels, et les journaux, avec d' énormes manchettes, plaidaient les uns pour l'une, les autres pour l'autre solution $»^{6}$. Selon Maurer, Corinthe et Athènes rassemblaient le plus d'avantages et après avoir donné des arguments en faveur de Corinthe (site, climat, position centrale par rapport à la Grèce) il finit par plaider ainsi pour Athènes : «Pour Athènes (comme capitale) concordaient tous les souvenirs sur la civilisation attique, les arts, les sciences, son éternelle gloire militaire. Construite près de Marathon et sur les superbes vestiges de l'antiquité classique, elle est située face à Salamine et Egine (...), les ruines des Longs Murs, le Monument de Cimon, l'Odéon, l'ancien Portique (Stoa), la prison de Socrate - où il a avalé, d'après ce qu'on raconte, la ciguë - le Parthénon et la Pnyx, où on croit encore entendre les paroles d'Aristide, de Démosthène et de Périclès... ». Et Maurer poursuit: "Chaque pas, chaque regard, tout rappelle les jours glorieux de la ville la plus renommée du monde Quel roi aurait pu choisir un autre siège pour son gouvernement, du moment qu'il détient le siège spirituel du monde ? C'est ainsi qu'Othon, après mure réflexion, a choisi Athènes» ${ }^{7}$. Comme on le sait plus que l'adolescent Othon c'est son père le roi Louis Ier de Bavière qui, de Munich, « influencé par les archéologues ${ }^{8}$, a tranché sur cette question dont la réponse devait 
paraître évidente. Son passé romain, la formation de son "goût néoclassique " par le sculpteur Thorvaldsen, «l'astre le plus prestigieux de la cour d'artistes que Louis 1er de Bavière avait réunis autour de lui ${ }^{9}$, avec notamment l'architecte Leo von Klenze, appelé à « corriger » le premier plan d'Athènes en 1834, a dû aiguiser sa perspicacité stratégique concernant le rôle que les antiquités joueraient pour le nouvel État.

Les raisons avancées par Léo von Klenze sont aussi explicites que celles de Maurer. Il justifie ce choix par «la situation exceptionnelle, les grands souvenirs et des visées de haute politique $»^{10}$. Et il ajoute: "Après l'Acropole, la ville de Thésée, la ville d'Adrien, nous aurons à montrer l'Othonopolis (...). Quels souvenirs, gloire, grandeur et espoir exprime chaque nom des sites de cette ville! Et tout cela est contenu dans un seul nom : Athènes ». Et le même plaidoyer inspire l'archéologue Ludwig Ross pour qui «toute l'Europe civilisée » ne peut qu'approuver le choix et le nouveau plan de la ville ${ }^{11}$.

6 Klenze l'architecte, Ross l'archéologue et Maurer le professeur de droit coutumier germanique à Munich et régent de Grèce, répondent ainsi aux arguments des opposants au choix d'Athènes. Pour Maurer particulièrement ce n'est pas par ignorance de la situation concrète de la Grèce mais, au contraire par connaissance des attentes de l'Europe. Le régent est convaincu de la nécessité d'instrumentaliser l'archéologie et l'histoire au profit de la politique et au service des tractations diplomatiques: «Les antiquités grecques, à part le fait qu'elles provoquent un grand intérêt des historiens et archéologues, ont avant tout pour le Royaume de Grèce une signification politique énorme. Car c'était l'idée de la Grèce antique qui inspirait à toute l'Europe le grand intérêt pour la lutte des héros de la nouvelle Grèce (...). Et de nouveau l'esprit de l'antiquité grecque est celui qui doit rester dans l'avenir le point d'attache entre la Grèce actuelle et la civilisation européenne $»^{12}$.

7 G.L. Maurer et les Bavarois procèdent donc à un acte politique. Le journal Athéna du 20 mai 1833 refuse Athènes au nom du développement économique et prétend que l'archéologie jouera contre le commerce, quand Maurer répond qu'elle œuvrera politiquement et économiquement pour la Grèce. Maurer aussi est contre les " touristes ", contre ceux qui jettent un regard superficiel sur la Grèce et ne s'intéressent qu'à son passé. Il est contre les Grecs qui se prennent pour des « anciens ». I1 est contre tous ceux - militaires ou philologues - qui portent des regards « unilatéraux» comme il l'écrit et surtout contre les transpositions et les généralisations qui, à partir d'une discipline, prétendent tout comprendre. Il fustige d'ailleurs à propos de la Grèce «l'ignorance de toute l'Europe (...) personne ne connaît rien de la réalité grecque, chacun voit les choses selon son propre prisme et transpose " ${ }^{13}$. Mais il sait aussi que l'utilisation de l'archéologie et de la « mémoire » ne sont pas neutres quant au devenir du commerce.

8 En octobre 1834, le journal Athéna revient de manière désespérée à la charge dans un article $^{14}$ où les mêmes arguments - de situation, de commerce, de transport - sont repris et à grand renfort d'autres exemples historiques. Babylone et Ninive construites sur l'Euphrate et le Tigre, Carthage et Alexandrie sur la mer, Rome sur le Tibre, Paris sur la Seine, Londres sur la Tamise, Saint Petersbourg sur la Neva sont appelées ainsi à la rescousse. Et puis de nouveau l'antiquité revient. Pour rappeler que pendant « les guerres persiques les Grecs vont dans le Péloponnèse selon Hérodote et Eschyle ». Que "Thémistocle abandonne Athènes pour Salamine ». Et qu'enfin : "Athènes s'honore parce qu'elle existe pour toujours à travers les souvenirs (...) Sûrement il n'est pas sensé de fonder les intérêts de la nation grecque d'aujourd'hui seulement sur des idées archéologiques et sur les ombres des morts ». 
9 Mais Athènes c'est la condition sine qua non pour construire pratiquement l'Etat néohellénique. L'abstraction Athènes fonctionne ainsi dans le sens de la sublimation de l'idée mais aussi de sa manipulation pour rassembler son territoire par la neutralisation des centres vitaux et rivaux du pays. Localisé à Athènes, le pouvoir politique abandonne le terrain où se situent les enjeux. De ce choix, il tire sa force : il se concentre en un point qui fédère physiquement et psychologiquement tous ceux qu'ailleurs leurs intérêts opposent.

10 Seule Athènes ville capitale à l'urbanisme " néoclassique » pouvait accueillir l'adhésion universelle des disparités locales. Dans la Grèce de 1833-34, il fallait inventer une Athènes. Elle était là. Et on l'a inventée.

\section{NOTES}

1. G. Burgel, Athènes. Développement d'une capitale méditerranéenne, Athènes, 1976, p. 141 et 250 [en grec].

2. Journal Athéna, n. 114, 20 mai 1833.

3. G.L. von Maurer, , Das Griechische Volk in Öffentlicher und privatrechtlicher Beziehung vor und nach dem Freiheitskamptee bis zum 31 Juli 1834, Heidelberg, 1835 [éd. Grecque : Athènes, 1976].

4. Ioannis Colettis, chef du parti français et futur premier ministre. Pour le général Makryannis, héros de la révolution, Colettis défendait le maintien de la capitale à Nauplie parce qu' « il avait construit beaucoup de maisons et d'ateliers sous un nom d'emprunt et en touchait les loyers (...) et puis, la ville étant petite, il manipulait sa clique comme il l'entendait ». Général Makryannis, Mémoires, Tome B, Livre III, Athènes, 1947 (1833-1843), p. 76 [en grec].

5. Johann Gottfried Gutensohn, (1792-1844). Proche de Louis de Bavière, architecte en chef de Munich, il est chargé de constructions à l'île de Syros. Il intervient pour que Klenze s'occupe de la révision du plan d'Athènes.

6. G.L. von Maurer, op. cit., p. 477.

7. F. Kreutzer, Discours à propos de la ville d'Athènes, mère de l'humanité, (en latin), Frankfurt 1826 (note de G.L. von Maurer) .

8. Sur le rôle de Louis $\mathrm{l}^{\mathrm{er}}$ de Bavière concernant Athènes : cf. A. Koumarianou et Y. Pétropoulos, in : Histoire de la Nation grecque, vol. XIII, Athènes, 1977, p. 58 [en grec] et K. Biris, Athènes du $19^{e}$ au $20^{e}$ siècle, Athènes, 1966 [en grec], p. 23.

9. M. Praz, « Le "Cavaliere Alberto“" , in : Goût néoclassique, Paris, 1989 [tr. fr.], p. 237.

10. K. Biris, op.cit., p.35.

11. L. Ross, Erinnerungen und Mittheilungen aus Griechenland, Berlin, 1863, [tr. gr. Athènes, 1976], p. 166.

12. G. L. von Maurer, op. cit., p. 544.

13. Ibid., p. 408-409.

14. Athéna, n. 184, 8 octobre 1834. 


\section{RÉSUMÉS}

La désignation d'une capitale pour l'État grec indépendant constitua une question politique cruciale, dont les échos résonnent aujourd'hui à travers l'architecture d'Athènes du XIX ${ }^{\mathrm{e}}$ siècle. L'auteur analyse ces implications politiques, cachant derrière les aspirations de la jeune nation hellène les intérêts des Grandes puissances, et la manière dont elles ont été traduites dans la nouvelle architecture d'Athènes, terrain de mise en œuvre des doctrines esthétiques de l'Europe occidentale du temps.

Choosing a capital was a crucial political question in the independent Greek state, and one can observe its echoes in the monuments of Athens coming from the $19^{\text {th }} \mathrm{c}$. The author analyzes these political implications, where the Great Powers interests hid behind the young Hellenistic nation. The way these implications have been transposed in the new architecture of Athens reflects esthetical dogmas of Western Europe at that time.

\section{AUTEUR}

\section{YANNIS TSIOMIS}

E.H.E.S.S., Paris 